\title{
CLIMATE CHANGE IN GAME THEORY CONTEXT
}

\author{
Gábor Kutasi, \\ $\mathrm{PhD}$ of Economics, assistant professor \\ Department of World Economy \\ Corvinus University of Budapest \\ H-1093 Budapest Fővám tér 8., Hungary \\ e-mail: gabor.kutasi@uni-corvinus.hu
}

\section{BIOGRAPHY}

Gábor Kutasi completed his PhD degree in Corvinus University of Budapest. He has worked at ICEG European Centre, Budapest, Hungary, as research fellow. He is presently assistant professor of economics at Department of World Economy, Corvinus University of Budapest. He is certified accountant and tax adviser. His research areas of interest are economics of climate change, fiscal policy, monetary policy, economics of monetary integration, economics of financial market integration, fiscal impacts of climate change.

\begin{abstract}
The aim of this paper is to survey the game theory modelling of the behaviour of global players in mitigation and adaptation related to climate change. Three main fields are applied for the specific aspects of temperature rise: behaviour games, CPR problem and negotiation games. The game theory instruments are useful in analyzing strategies in uncertain circumstances, such as the occurrence and impacts of climate change. To analyze the international players' relations, actions, attitude toward carbon emission, negotiation power and motives, several games are applied for the climate change in this paper. The solution is surveyed, too, for externality problem.
\end{abstract}

Key words: game theory, climate change, common pool resource, negotiation game

JEL C70, Q54

"The issues of how best to govern natural resources used by many individuals in common are no more settled in academia than in the world of politics" Elinor Ostrom (1990)

\section{Introduction}

According to O'Hara (2009), “[...] global warming hypotheses have been a contested terrain as advocates sparred with critics, resulting in controversy and analysis, but no firm resolution either way at the level of public debate. All this has suddenly changed in the light of the 'global warming' thesis gaining the upper hand. The influence of [...] publication of the IPCC Report (2007a,b,c,d), the Stern Review (2007), the UNDP Report (2007), and the Garnaut Report (2008) [...]have meshed with the election of more moderate governments in several continents to change the public view of these matters. 'Climate change', as it is now called, has become an accepted institution, even by most of those who previously argued against 'global warming.'."

Climate change is a long-term challenge for the Earth, and preventive actions should be taken very soon before the impacts meanwhile it is very uncertain to forecast the exact far future damages of different regions when exact scale of regional warming is an unsure variable in the equation of economic impacts. Scenarios and action plans have been developed, but there is an important factor that makes their execution questionable: the hesitation of decision-making stakeholders. Hesitation is rooted both in uncertainty and expectations concerning each other's strategies. Such a survey environment also demands game theory to understand and forecast the strategy of stakeholders. 
However, Rubas et al. (2006) establish, that "game theory has not been widely used in applications of seasonal climate forecasts largely because of the increase in information requirements and increased methodological knowledge necessary to develop and solve games. [...] Though rarely used in studies on climate forecast problems, game theory has been used in climate related studies such as climate change studies (Ward 1996, Forgo et al., 2005) and climate variability studies (McKelvey et al., 2003)." The previously quoted Rubas et al. (2006) give a very broad view of the economics and survey methodology of climate change, detailing the game theory as well. Besides Forgó et al. (2005), very specific modelling and surveys of the negotiations have been created by Courtois, P. (2002), Yang (2003), Courtois \& Tazdaï (2007), and Pinto \& Harrison (2003).

The study provides an overview of the application possibilities of game theory to climate change. The characteristics of games are adapted to the topics of climate and carbon. The importance of uncertainty, probability, marginal value of adaptation, common pool resources, etc. are tailored to the context of international relations and the challenge of global warming.

The complexity of the theme also requires borrowing some themes from international relations theories, behaviourism, ecological economics, and international political economy. As a basis for application of the game theory, the general theses by Ostrom (1990), Owen (2008), Harsányi \& Selten (1988), Olson (1965), Myerson (1997), Dixit \& Skeath (1999) and Harding (1968) are applied. ${ }^{1}$

\section{Characteristics of games}

In the case of modelling of pro-actions and reactions for changing temperature, the characteristics of events, actions and behaviours must be known. In climate change, uncertainty is a dominant character. Technically speaking, uncertainty means there is no saddle point in the game. (Owen 2008) This means that the payoff of the game is not sure but depends on the actors' expectations and their probable reactions on each others' actions, or on the probability of certain external events. Especially in the field of climate change, uncertainty is accumulative $^{2}$ (see Figure 1). There are even scientific disputes whether the change of average temperature is really taking place, and if so, whether it has been caused by the $\mathrm{CO}_{2}$ emission from human activity. (About the challenges of economic forecast see Rubas et al. (2006).)

If climate change is taking place globally, it does not mean a generally same rate of temperature change in every region and territory of the Earth. (It is possible that a more or less rise in temperature or even cooling down will be a likely outcome in certain regions.) The physical impact of the various effects can be different. In some regions, the rise of sea level might take costal territories, in others strong diseases might break out due to warmer climate, in still other territories the agricultural lands would dry out, and somewhere else the disappearance of ice and snow would create land cultivation opportunities or ruin winter tourism, etc. But what is the likelihood at the level of a continent, a country, a county or a city/village? If there are more scenarios, what mitigation and adaptation actions are effective? What is the critical mass or scale of action? Will the actors wait for each other to act? Who should act first? Should the state intervene, motivate, initiate? And so on. If such uncertain probabilities are accumulated (namely multiplied) the final likelihood of effective actions can be low.

Figure 1 Increasing uncertainty in climate change (CC)
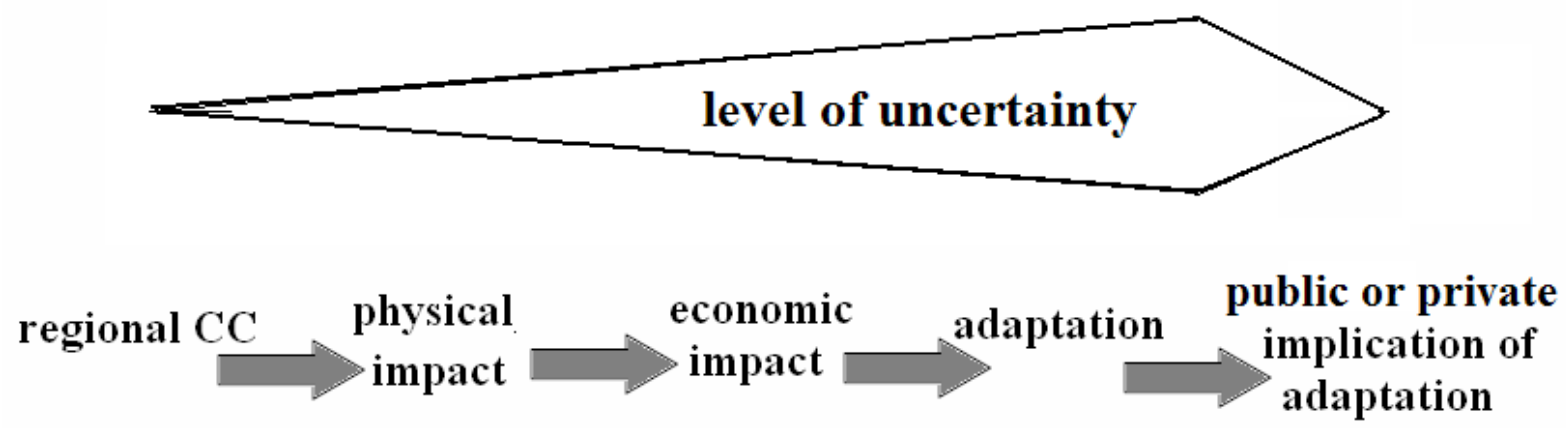

Source: Simplified adaptation from Stern (2007) and O'Hara (2009)

\footnotetext{
${ }^{1}$ The author was supported by TAMOP-4.2.1.B-09/1/KMR-2010-0005 project in the research of this paper.

2 About circular and cumulative causation and irreversibility see Thorstein Veblen, Gunnar Myrdal, Nicholas Kaldor, K. William Kapp and Nicholas Georgescu-Roegen referred in Berger 2008, 2009, about cumulative uncertainty see Frank Knight (1921), J.M. Keynes (1921, 1936), and G.L.S. Shackle (1970)
} 
The source of uncertainty can be asymmetry in information, moral hazard, irresponsibility (no ability to carry out commitments), negative selection (counter selection), decentralized governance, myopic self interest. Asymmetry in information can be rooted in technology and science difference or different positions in information reception streams. However, uncertainty can also be used as weapon in climate negotiations to keep opponents guessing, thus making them uncertain and slow. (Dixit \& Skeath 1999, p. 187, 264, 272)

The latter, in case of climate change and the related carbon emission, is not very likely if we consider the global information systems of the $21^{\text {st }}$ century. Moral hazard, namely causing risk and cost for someone else by one's behaviour or decision is a very typical occurrence in negative externality situation just like environmental damage as $\mathrm{CO} 2$ emission. Irresponsibility can be understood as sociopath behaviour, also adoptable into international relations just like North-Korean nuclear threat and war threat psychosis. In case if carbon emission, irresponsibility could mean the ignorance of negative global externalities from emission. Negative selection is very theoretical in case of climate change games. Generally, it means that always the lower quality, less credible, less able etc. option or actor is preferred. Among the behaviour games we will see cases, when the smaller/weaker actor can enforce its own preference on the bigger/stronger actor (see called bluff and suasion games). Decentralized governance is relevant in game uncertainty and climate change as it increase the number of actors and move further the scale of problem (global) and level of competence (regional) from each other. Thus, the likelihood of free riding will increase. Possible occurrence of myopia as uncertainty factor means ignorance of long-term externalities for short-term profit, welfare, comfort etc. The examples of peace treaties of World War I or absence of green-house-gases treatment can be mentioned for myopia in international relations. (Keohane, 1984, p. 92-98)

The payoff function of a game means the composition of probable individual cost-benefit balances of different scenarios for the same problem. The total payoff of a game can be negative, zero and positive sum. It is possible also to have variable sum game if the sum of total payoffs is not constant in different scenarios (outcomes). Static and dynamic games can be distinguished, as in static means constant, dynamic means changing preferences. (Owen, 2008) The exiting and challenging aspect of payoff matrix definition related to climate change is that it is the result of a national welfare optimization in relevance to green house gas damage due geophysical and socioeconomic transformation.

In case of climate change, because of its complexity and high uncertainty, the variable sum and dynamic approach is the most useful to model the behaviour of actors of international relation. As certainty of occurrence and local/regional impact of temperature change gets stronger, it has repercussion on the preference of decision makers in the international space. Change in preferences can be caused, also, by change in political leadership or regime. (Keohane, 1984, p. 116) For example, the end of Clinton governance and the beginning of G.W. Bush governance had resulted significant difference in the U.S. attitude to the Kyoto protocol in the presidency level. Very complex structure of possible choices can result also variable international community payoff in dependence of multi-country actions. And here comes the question of timing dilemma: The further we are before the change of temperature and its physical impact, the higher is the uncertainty of the occurrence of climate change, thus the lower is the motivation to mitigate, however the cheaper and the more efficient is the mitigation. The closer we get to the realization of climate change impacts, the higher is the certainty but the mitigation or adaptation cost, too. Namely, the mix of probability, the scale of temperature change, the current cost of adaptation and the expected damage will determine a marginal value for the private and public and international actors as benchmark to decide the timing of mitigation/adaptation.

In game theory, the assumption of a rational player entails the maximization of individual benefits. This theorem introduced the importance of conditionality, since the probability of certain alternatives depends on circumstances. (Myerson, 1997, p. 12) In the timing of start-up the actions, there is an important factor, namely, when it does worth to mitigate or adapt. This can be simply described by the net present value (NPV) calculation. Just as generally, the aim of an economic actor is to maximize the net marginal benefit of the action. (CEPS\&ZEW, 2010)

$$
\mathrm{F}=\max \{\mathrm{MB}-\mathrm{MC}\}
$$

Until MB > MC, namely marginal benefit is bigger than marginal cost, there is no motivation to start or extend the adaptation. For planning of timing of adaptation or mitigation to climate change, this maximization should be dynamic, so the optimum NPV of adaptation cost and climate damage is looked for. (Rubas et al., 2006)

$$
\mathrm{NPV}(\text { climate change })=\mathrm{PV}(\text { adaptation cost })-\mathrm{PV}(\text { climate damage })
$$

According to the model of Hasson et al. (2010) with all-or-nothing trade-off between the preventive mitigation and the reactive adaptation, the timing depends on the expected payoff for having and having not a disaster. 
In Hassons et al. (2010) model, the expected payoff depends on the probability of the disaster, the vulnerability of the individual, the budget necessity of mitigation, budget necessity of adaptation, existing financial instruments. Investment in mitigation lowers the probability of a disaster for all subjects, while adaptation lowers the actual cost of a disaster only for that individual subject. The total mitigation by the group is divided by the total budget available to all subjects, so the more people that invest in mitigation, the lower the probability of disaster.

Investment in adaptation may have on the economy other than preparing for a climate change disaster. The cost of a disaster is also affected by the degree of vulnerability. The more vulnerable are the actors, the higher will be the damage of a disaster. Likelihood of disaster is determined by "total mitigation and an element of chance", which means partly endogenous and partly exogenous determination. Namely, the return from mitigation is larger if all players mitigate, but there is still risk of a climate change disaster.

That is why the social dilemma is described by the marginal per capita return (MPCR) for mitigation (m) and adaptation (a) in the followings:

$$
\mathrm{MPCRm}<\mathrm{MPCRa}<\mathrm{n} * \text { MPCRm },
$$

where $\mathrm{n}$ is the total number of actors.

The relation between MPCR values expresses, that because of the exogenous chance for disaster, the cost is too much, if every one mitigated, since it can not prevent absolute surely the disaster. That is why it is expectable, that, depending on the above mentioned factors, there will be some actors, who will and should not mitigate, if the community/society want to pay the optimum cost for prevention.

The players of a game are not necessarily rational decision makers, but they could be iterating actors. Namely, strategic choices can be made through experiments of strategic alternatives. This version of strategic games is analysed by the evolutionary game theory. The iteration presumes the importance of dynamics and the frequency of findings from the competition of strategic alternatives. (Maynard Smith, 1982; Weibull, 1995; Dixit \& Skeath, 1999) In evolutionary theory and in the evolutionarily stable strategy model by Maynard Smith (1982), it is important, to have more opportunities to attempt. In the ecosystem, the opportunity for several attempts is ensured by the high number of individuals in a population. In international relations, the repetition of a test is possible as the states are immortal and infinite actors (even though in some cases, some states disappear). In this way of decision-making, primarily not the absolute but the relative quality and the frequency of attempts will determine the adequate or acceptable strategy among the alternatives. Some examples for evolutionary games are the following: hawk vs. dove, war of attrition, stag hunt, tragedy of commons, prisoners' dilemma, assurance game, chicken game. (Dixit \& Skeath, 1999, p. 430-451)

For example, the hawk vs. dove game is a situation when there is one type of player, such as a group of countries, who can choose among alternatives. The hawk strategy variation means taking as much resource as possible and levy as much cost on partner as possible. The dove is on the contrary. In a dual game, both players can try both types of alternatives. The war of attrition is a variation of the hawk vs. dove in so far as there are alternative resources. If hawk picks one, the dove still has other resource seeking opportunities. (The hawk strategy is actually called bourgeois strategy in the latter game.) (Maynard Smith, 1982; Dixit \& Skeath 1999, p. 447-450)

Especially in the case of negotiation games in international negotiations, the interesting aspect is the number of replication options, whether it approaches to limited number or to infinity. The number of possible replication will determine whether game has a finite or infinite horizon. (Kandori, 2006) It is very likely that the existence of a saddle point will limit iteration. Meanwhile, more equal total payoff functions with various distributions will induce a permanent war of attrition, thus creating a game that approaches to infinity. In the case of a finite game, the distance of the horizon can strongly determine the approach of the players. For example, global warming seems so far in the future for mortal or short-sighted economic and political actors that some of them view it as an infinite game. Just as if there were infinite time to test the different alternatives. The U.S. governments have been switching between contract and market approach concerning the internalization of carbon emission. Republican administrations insisted on the market-driven pricing, while the Democrats supported the U.S. join the Kyoto protocol. However, infinite games can be played by the social norms of the so called folk theorem. (Abreu et al., 1994) Kandori (2006, p. 1-3) mentions three general ways to achieve efficiency in infinite games: competition, contracts, long-term relationship. The general example is two gas stations next to each other with the three alternatives on pricing. The trigger strategy will determine the progress of iteration. The trigger strategy depends on the character of the players: whether they are doves or hawks, active initiators or passive followers, aggressive competitors or collaborating, and also on the assessment about the opponent.

Climate negotiations can be regarded as an infinite repeated game with the three alternatives. For example, adhering to an agreement on carbon emission limits equals with contracting. Or, everyone becomes a free rider and do not limit emission at all, thus the competitive Nash-equilibrium is enforced by a long-term warming damage. Frequently, temporary deviation from the quota with return to the norm later can be considered a long- 
term cooperation situation where players always want to realize their best short-term payoff, but after deviation, they regularly give up the Nash-equilibrium. (About repeated games see Myerson, 1997, p. 308-365)

The microeconomic game theory examines individual strategies in dependence of expectation on other individuals' behaviour. In the mainstream international political approaches (realism by Morgenthau and Kenneth Waltz or constructivism by Alexander Wendt) consider the actors of international relations just like rational individuals in the microeconomics. Thus, games can be transplanted to international relations, like treating the global climate change and regulation of carbon emission. In theses of Keohane (1984, 1989) and Keohane \& Hoffmann (1991) the application of game theory is to analyze the international relations is exemplary. This literature uses variable sum games, dilemmas, dynamic preferences, uncertainty, to explain cooperation, harmonization or conflicts. It is also important in international relations theory, that Keohane (1984) applied the bounded rationality by Herbert Simon when not maximization of net benefits, but satisfactory solutions are accepted, or such principals are driving the participants' decisions as the empathy in relations, humanitarianism, pacifism, Wilson's moralism, internationalism and reciprocity.

\section{CPR-problem in climate change}

The examination of international relations with the instruments of microeconomics can be started with a characteristic occurrence which is very often in the decentralized international space. It is the common pool resource (CPR) problem. In the microeconomics, this problem was described and explained by Garrett Hardin (1968) as the tragedy of commons. In the common herding field in community ownership, the rational individual herders' behaviour is to add more and more animals onto the field and this way the cattle will overgraze, thus ruin the grass field. This type of "motivation to increase the using without limit in a limited world" (Hardin, 1968 , p. 1244) is very often temptation in case of the international resources, just like the climate. The climate, more precisely the average level of temperature in a region can be understood as a resource for certain type of living, land cultivation, transportation, access to costal territories, use of technologies, health conditions etc. This resource - according to natural sciences - can be ruined by excessive carbon-dioxide emission. So, the common pool resource and its possible overuse got identified. In optimum case, the users of the common pool resource should agree, how to sustain and finance (or operate) this resource. But Olson (1965) recognized according to the rational individual model of microeconomics, that if someone can not be excluded from the use of the resource, he/she is not too much motivated to contribute to the financing, sustaining of it, but to behave as a free rider.

Ostrom (1990. p. 8-21) gathered the developed solutions for CPR problem: the Leviathan, the Privatization, the self-financed contract-enforcement. The Leviathan model related to Hobbes, who saw the solution of overuse of community resources in a strong central power, which punishes the excessive access and this way changes the original payoff of excessive users. This model has two weak points: the corrupt executives will cancel the penalty, and the central authority might operate with incomplete information, thus can not effectively punish. Besides, in international relations, in post-hegemonic cooperation (or multi-polar system, see later) there is no chance to have an external strong power (the Leviathan) threatening the carbon emitters with sure punishment. (Ostrom, 1990, p. 12) The second option, the privatization, according to Demsetz (1967) and Smith (1981), means that the common pool resource should get distributed to private ownerships, and private owners will take care for the completeness of own share. In case of climate impacts and temperature it is an irrelevant option as this is an indivisible resource. The third solution, the self-financed contract-enforcement means that the users watch and control each other, as they know mostly the "capacity" of the resource, and as they are present in the use, they can have complete information about the state of the resource and the behaviour of other users. In micro level, this is a broadly used solution e.g. in case of issuing fishing, angling or hunting licences. That is the way what has been realized by the Kyoto protocol, too. ${ }^{3}$

\footnotetext{
${ }^{3}$ However, the mentioned solutions tries to create a coordinated game on the use of CPR, Ostrom (1990, p. 4250) still identified institutional problems rooted in uncertainty and difference in mobility, damage and dependency of users. The problem of supply raises the question: Why would the members of a society be motivated to supply the institutions governing the common pool resources? New institutions and rules, besides solving an existing CPR problem, create new CPRs. The problem of credible commitments means, no one wants to be looser or - as written by Ostrom (1990) - "sucker", namely, no member is willing to contribute and risk any cost if other members' commitment got questionable. The problem of mutual monitoring enlightens the necessity of voluntary activity which burden cost of punishment on the participants. The appropriation problem raises the question, how to allocate in spatial and temporal horizon. The provision problem points on the necessity of appropriate construction and maintenance. (About credibility problem see also Dixit \& Skeath (1995, p. 315-320).)
} 
In case of the carbon emission as an international CPR problem, the emission can be understood as a negative CPR since more emission is worse, and its opposite (positive) CPR is the stable temperature and all the economic and social opportunities related to this climate. The CPR problem is that CO2 emitting countries do not want to bother with the level and impacts of emission, do not want to join any reduction targeting or do not want to take the cost burden of mitigation and adaptation with reference to uncertainty.

From the view of organization theory applied for international organizations, there is a very general practice to try to solve international CPR problems. Namely, it is very close to Coase's ownership school approach that recommends the delegation of the ownership to those who can distribute or trade the use and set the price of the resource in the most efficient way. (Coase, 1960) In international relations, it means many cases, that countries create international organisations who get the right to regulate, monitor, maybe penalize, make decisions, do justice to disputing parties etc. In case of international oceans, external space, nuclear energy, international trade or monetary regimes there are such international owners of the common pool resources (many times with questionable efficiency). In case of carbon emission, such international organisation (a Leviathan) has not been established, but the ownership has been split among international country players who can have control over the private emitters and trade quotas with each other, thus set the current global price of ton of $\mathrm{CO} 2$ emission.

Table 1 and table 2 shows such prisoners dilemmas for CPR problem which are applied for climate change mitigation/adaptation strategies. Table 1 illustrates a two countries (or two groups of countries) situation, where the dilemma is to pay the cost of mitigation and adaptation or not to do anything for lower carbon emission. If a country chose to mitigate and adapt, she must pay the cost (C). Depending on strategies, in a simplified version, if both players mitigate, there is no change of temperature, so cost of damage is zero (T0). If one of them does not act, than at least 1 Celsius warming happens, so some economic damage will be realized (T1). If no one acts, more serious, let us say, 4 Celsius warming occurs with bigger economic damage.

Table 1 Climate change prisoners dilemma, country to country

\begin{tabular}{|l|l|l|l|}
\hline & \multicolumn{4}{|c|}{ Country A } \\
\hline \multirow{4}{*}{ Country B } & STRATEGIES & Mitigate and adapt & No action \\
\cline { 2 - 5 } & Mitigate and adapt & $\mathrm{C}+(\mathrm{T} 0)$ & $\mathrm{T} 1$ \\
\cline { 2 - 5 } & No action & $\mathrm{T} 1$ & $\mathrm{~T} 1)$ \\
\hline
\end{tabular}

$\mathrm{C}=$ cost of mitigation and adaptation, $\mathrm{T} 0=$ no temperature change, zero damage, $\mathrm{T} 1=$ damage, caused by rising temperature by 1 Celsius, $\mathrm{T} 4=$ damage, caused by rising temperature by 4 Celsius, $\mathrm{T} 4>>\mathrm{C}, \mathrm{T} 4>>\mathrm{T} 1$

Source: author

The game of Table 1 is an evolutionary case since it can be understood as an example for the hawk vs. dove game, as the preservation of the current climate is a "resource" without alternatives. A hawk-meets-dove situation is when the hawk country would be the 'no action' country levying all mitigation cost burden on the partner (dove) country. Note, however, that the prisoners' dilemma can actually be interpreted as an evolutionary stable strategy if there is Nash-equilibrium. (Weibull, 1995) In this case, Maynard Smith (1982) calls it 'assessor' strategy. The assessor analyses the opponent player and will choose a strategy that matches the opponent's character the most. Thus we can get to the symmetric and asymmetric variants of dilemma just like the called bluff, the stag hunt or the suasion game (see below).

Table 2 Climate change prisoners dilemma, public to private players

\begin{tabular}{|l|l|l|l|}
\hline & \multicolumn{4}{|c|}{ Public Policy } \\
\hline \multirow{3}{*}{ Private Economic Actors } & STRATEGIES & $\begin{array}{l}\text { Subsidies the cost of } \\
\text { adaptation }\end{array}$ & $\begin{array}{l}\text { No subsidies for private } \\
\text { sector }\end{array}$ \\
\cline { 2 - 5 } & Pay the cost of adaptation & $\mathrm{C} /(1-\mathrm{n})+(\mathrm{T} 0)+(\mathrm{T} 0)$ & $\mathrm{C}+(\mathrm{T} 0)$ \\
\cline { 2 - 5 } & $\begin{array}{l}\text { Expect action from } \\
\text { Public Policy }\end{array}$ & $\mathrm{C}+(\mathrm{T} 0)$ & $\mathrm{T} 5$ \\
\hline
\end{tabular}

$\mathrm{C}=$ cost of mitigation and adaptation, $\mathrm{n}+(1-\mathrm{n})=1, \mathrm{~T} 0=$ no temperature change, no damage,

$\mathrm{T} 5$ = damage, caused by rising temperature by $5{ }^{\circ} \mathrm{C}, \mathrm{T} 5>\mathrm{C}$

Source: author

Table 2 shows an intra-national situation with public and private group of players, where the dilemma is to pay the cost of mitigation and adaptation or wait for the other type of national actors. Namely, the public policy makers can decide whether they pay subsidies and introduce green taxes to motivate lower carbon emission, or do not subsidize the private sector at all in mitigation/adaptation. The private sector players can decide, whether they participate in financing, they can share the cost $(C / n+C /(1-n))$, and they can reserve the current 
temperature, in a simplified version, so they will not suffer damages (T0). If only one of the types (public or private) is willing to finance, but the other one is reluctant, cost of adaptation (C) will be levied on the willing player, but, let us say, the economic damages can be avoided (T0). If no one is ready to finance, the economic damage will be extremely big (T5) for both of them.

These games are calibrated so that both players' 'no action' strategy is so threatening that it must be avoided (if T4 damage is bigger than $\mathrm{C}$ cost and T1 damage, and T5 $>\mathrm{C}$ ). But co-action is not secured. In Table 1, the co-action depends on the relation of $\mathrm{C}$ and $\mathrm{T} 1(\mathrm{~T} 0=0)$. If $\mathrm{T} 1>\mathrm{C}$, it is worth to mitigate, otherwise it is rational to wait for the other player. In Table 2 , it is obvious that both $\mathrm{C} / \mathrm{n}$ and $\mathrm{C} /(1-\mathrm{n})$ is bigger than zero, so it is rational to wait for the other player. This way of thinking leads us to the no action + no action payoff in both games, heading for a trouble that can threaten with both players acting at least individually. But the result is that they wait for each others to act so that they can return to passivity again, etc. It can be established that there is no saddle point in the two examples. Of course, the matrixes can be rewritten in a dynamic view, as time passes, T0 or T1 damage cannot be limited, but will increase. The same can happen with T4 and T5, or even with C, especially if probability is introduced since neither of them are constant.

Setting emission quotas and watching each other for control is the practice of self-financed contract enforcement by Ostrom (1990) or the long-term cooperation of infinite repeated games by Dixit \& Skeath (1999, p. 347-354). Such games have a serious weakness called imperfect monitoring. (Abreu et al., 1990,; Fudenberg et al., 1994; or repeated games with incomplete information by Myerson, 1997, p. 364) The continued payoff changes when a player deviates. Imperfect monitoring is able to signal deviation but is unable to identify individual deviations. The only way to deter leakage is to punish all the players simultaneously. (Dixit \& Skeath, 1999, p. 356-358) This will result a community loss. Thus, the penalty cannot be levied on the free rider, and will lose its disciplining power. Kaldori (2006, p. 9-11) described the following climate change case to imperfect monitoring:

"For example, a country may not verify exactly how much $\mathrm{CO}_{2}$ is emitted by neighboring countries. [...] Published meteorological data indicates the amount of $\mathrm{CO}_{2}$ emission [...]. According to the nature of the signals, repeated games with imperfect monitoring are classified into two categories: the case of public monitoring, where players commonly observe a public signal, and the case of private monitoring, where each player observe a signal that is not observable to others. Hence, the $\mathrm{CO}_{2}$ emission game and the joint project game are examples with imperfect public monitoring (published meteorological data and the success of the project are publicly observed)."

\section{Behaviour game examples for climate change practice}

Behaviours related to climate change be easily modelled with two-player games. "Game theory is concerned with the actions of individuals who are conscious that their actions affect each other." (Rasmusen, 1992, p. 21) According to Ravenhill et al. (2005) the following games can be applied in international relations: for symmetric (equal) actors, the basic prisoners dilemma, the coordination game (also known as battle of sexes), the assurance game (also known as stag hunt) and the chicken game; with asymmetric (weaker vs. stronger) actors, the called bluff, harmony and suasion games.

The prisoners dilemma (see Figure 2) is a simple example to demonstrate the decision dilemma of situation with different payoffs depending on the partner's action. (Dawes, 1973; Dawes, 1975; Harsányi \& Selten, 1988) This is a no-communication game, when the players must deduct each other's strategy from past experience. This dilemma is the basis of the following modified situations. It could be good a framework to model the following: Shall a participating country exceed the settled emission quotas? Cheat or not cheat on emission reports? Do short-term individual and long-term global interests meet in $\mathrm{CO}_{2}$ emission?

The coordination game is a situation when cooperation has added value (see Figure 3). The original game is that the primary value for the husband and the wife is to be together, the secondary is to enjoy their different favourite entertainment (football vs. opera). In this game, the optimum (maximized total payoff) can be achieved if one of the partners is dominant or selfish, and the other one seeks the partner's preference. Otherwise, the primary value will not be realized. This is a good base game for those games when one of the actors must yield to pressure. For example, the rise of temperature might cause desert in Europe, but melt ice in Siberia, thus European agriculture will be damaged, but Russian agricultural capacities will be bigger. Someone must yield and give up their own benefits for the partner's favour. Climate change can be prevented, but Russia will not have more lands for cultivation, or European lands will become deserts (not cultivable). 
The assurance game ${ }^{4}$ describes a state when players are unable to seize an opportunity for cooperation that seems obvious. There is one best solution, and if it is spoiled, the worst payoff will be realised. That is why players are very cautious and do not act in uncertain circumstances, but wait for the other's action or their own certainty. However, after a while, the cost of passed time matters so the players will accept the second best solution (see Figure 4). This is a game without motivation for free riding. This game models e.g. the situation when small or less developed economies wait for large countries to initiate.

The chicken game is a useful framework to describe a situation when there are two (or more) opposite approaches, opinions, interests to be realized at any price by the players (see Figure 5). The biggest damage (negative payoff) will be realized if all players insist on their own ideas, principles etc. and never give them up. The stubborn behaviour is motivated by the cost or loss caused by giving up their own preference. A climate related example is when, during the Bush era, the U.S. government insisted on a market approach of and market solutions to carbon emission damages, while the EU insisted on international regulations and quotas. The conflict could have been cancelled only by a change in the U.S. governance (democrats returned to majority in Congress and Obama became president).

The called bluff is the asymmetric game for free riding by a weaker/less developed/smaller player. There are cases when the weaker one can enforce the stronger one to choose the weaker one's preference and this way avoid a bigger cost or loss (see Figure 6). The weaker one's preferred bargaining position must be rooted in a difference of vulnerability or resource availability for the advantage of the weaker in the given case. General international examples: The German and Japanese states defeated in the World War II could use undervalued currency in the 1960s and this way gain higher growth financed by their export markets. (Ravenhill et al., 2005) In the climate topic, the empirical example for the called bluff is the case when emerging countries like China or Brazil are asking compensation for participation in the Kyoto protocol for $\mathrm{CO}_{2}$ reduction. This would mean extra costs and lower payoff for highly developed countries, but at least they could get closer to their objective, lower global carbon emission as a second best way. Meanwhile, the emission cut would be cheaper for the emerging countries, and they can also enjoy the benefits of less or zero global warming, thus they (i.e. the less developed) could reach their own first best outcome. The basis of the whole situation is that the highly developed countries are actually more vulnerable in this case, and emerging countries can blackmail them with ruining the mitigation plans by staying out of the carbon regulation.

The harmony (Figure 7) and the suasion (Figure 8) games are specified asymmetric games with communication between players. The aforementioned games assume no communication, only individual deductions about the partner's strategy. The harmony game is the case when cooperation is the best solution. For a climate example, without mitigation every big power of the Earth will lose costal territories as sea level would rise. Keohane (1984) understood the harmony situation as an automatic, invisible hand operating the international relations perfectly, because in that case there is no externality, so no motivation for free riding. Suasion (convincing) means a called bluff with communication, when one player can convince the other in negotiation to accept the second best payoff to secure the first best payoff for the first one. E.g. China refers to the cost of the change of outdated manufacturing technology as a reason to get financial compensation for its participation in the Kyoto protocol. A special case of suasion is the hegemonic stability, when there is one power enforcing its own first best payoff and convinces its allies to accept the second best payoff. In the global order of $21^{\text {st }}$ century, non-hegemonic but post-hegemonic cooperation or multi-polar/non-polar systems can be mentioned (see Haass, 2008; Ikenberry, 2008). Obviously, a multiplayer model is also possible by using matrixes or vectors in formulating community or individual behaviour (see Owen, 2008; Osborne and Rubinstein, 1996; Forgó et al., 1999).

\footnotetext{
${ }^{4}$ Briefly stag hunt; stag is a very valuable trophy for the successful hunter and good meat for everyone, but a missed shoot will threaten all other animals. That is why players are very cautious. But if a long time passes without shooting, any other type of meat will become good, and this will accept a second best solution: less valuable meat and less valuable trophy.
} 
Figure 2 Prisoners dilemma

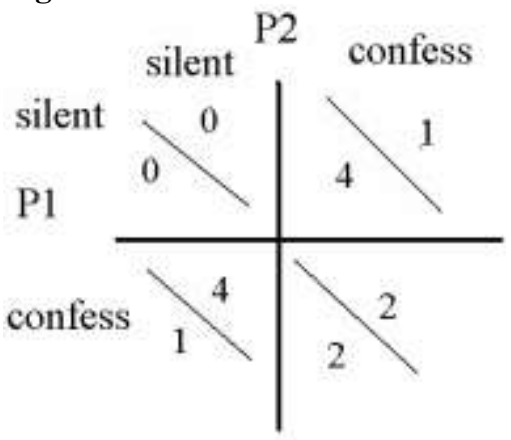

Source: Ravenhill et al., 2005

Figure 3 Coordination game wife

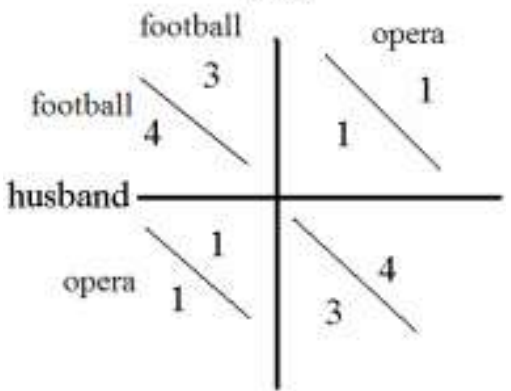

Source: Ravenhill et al., 2005

Figure 4 Assurance game (stag hunt)

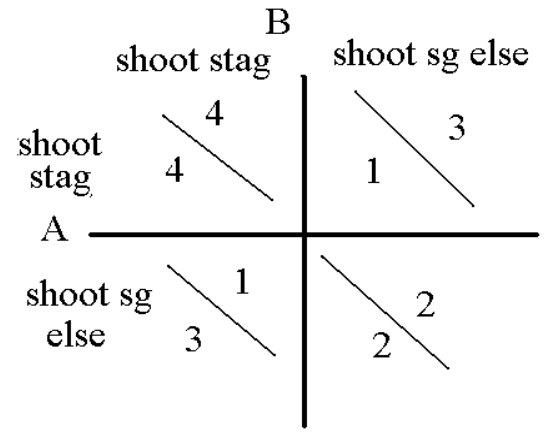

Source: Ravenhill et al., 2005
Figure 5 Chicken game

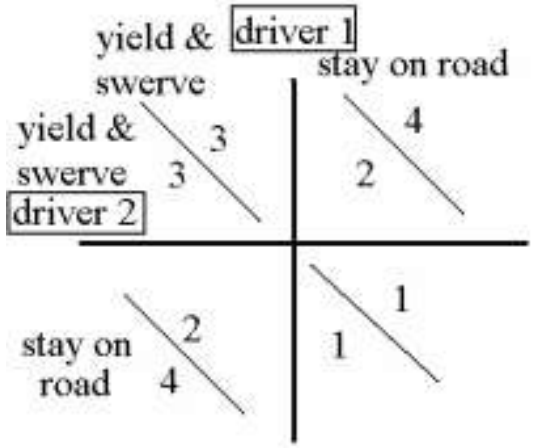

Source: Ravenhill et al., 2005

Figure 6 Called Bluff weaker

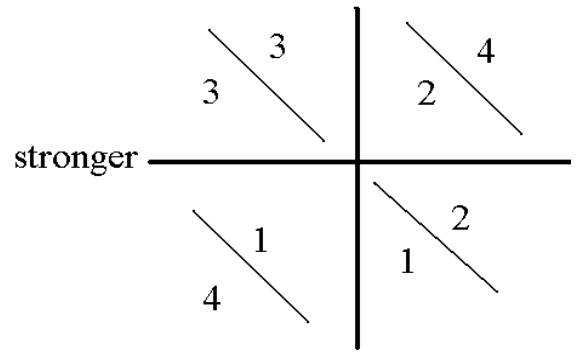

Source: Ravenhill et al., 2005

Figure 7 Harmony

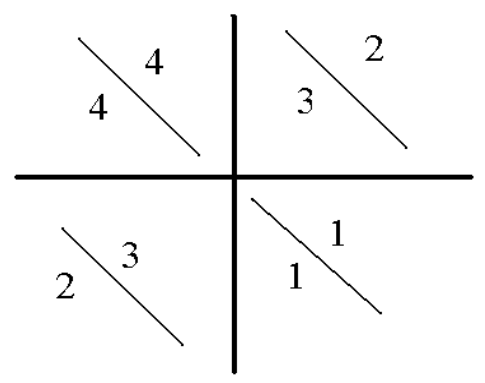

Source: Ravenhill et al., 2005

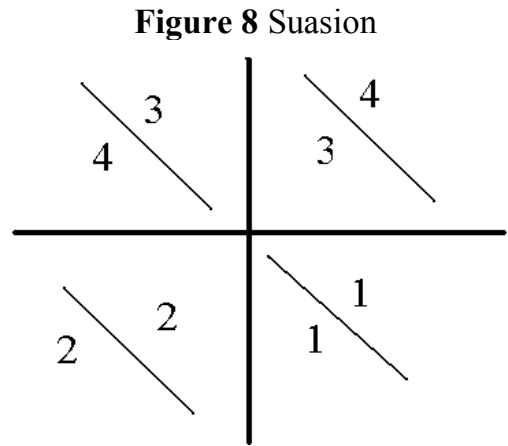

Source: Ravenhill et al., 2005 


\section{Negotiation games of climate change}

Negotiation games are about the enforcement of bargaining positions, i.e. relative power. Enforcement demands two factors to be hand in hand: power and wealth. As Keohane (1984) cited the definition of wealth by Karl Polányi and the power definition by Hans Joachim Morgenthau, wealth is the mean of satisfying material want, and the exchange value of marketable goods and services; power is the control over others' minds and actions, or control over other actors' play in the process of satisfaction. The eternal question is how to use the power to increase wealth or how to use wealth to increase power? ${ }^{5}$ Negotiation games can be used for modelling the process of carbon emission negotiations related to climate change. In literature, it practically means the modelling of strategies in the Kyoto process.

In negotiation games, the significance of vulnerability of the players and intensity of power competition is high. The determining factors of climate change negotiation games and the payoff of players are gathered by Hasson et al. (2010) as follows:

- Probability of warming or disaster, or expected change of temperature

- Marginal per capita cost of mitigation

- Marginal per capita cost of adaptation

- Share of cooperating partners from the total group of actors

"There has been a lot of research devoted to bringing together game theory and climate change negotiations. Simultaneous move non-cooperative (e.g. Nordhaus and Yang, 1996; Peck and Tijsberg, 1999) and classical cooperative models (e.g. Barrett, 1994; Carraro and Siniscalco, 1993; Chander and Tulkens, 1995) dominate the scene. Ciscar and Soria (2002) were the first to suggest the use of sequential (extensive form) games to describe and analyze the dynamics of the post-Kyoto negotiations in which reactions to previous moves of the players are taken into account at any decision point." (Forgó et al., 2003, p. 252)

Since negotiation can be a finite or infinite game, trigger strategy must be taken into account whether it is competitive, contracting or long-term cooperative. The first note mentioned by Kandori (2006) according to folk theorem is that there could be multiple equilibria in repeatable games if there are subgames. (Abreu et al., 1994; Dixit \& Skeath, 1999, p. 156-162) The cost of mitigation can be distributed variously to prevent global warming. The second note is about the credibility of threat and penalty in the case of unilateral free riding. How serious and certain and perceptible are the damages for the players? The third note is about the horizon of negotiations. How far can countries postpone starting to take mitigation actions? Which countries are being increasingly abandoned by polluting industries and activities, and which ones are targeted in the relocation process of manufacturing? High-tech energy production and declining manufacturing means a gradual exit from carbon emission activities by post-industrialized countries. Thus in an ultimate version, their strategies shall not be taken into account by the emerging countries.

In the development of negotiation game models, two directions can be discovered in literature. The first is a sequential modelling of multi-participant decision-making based on the Harsányi model and the Aumann model (Harsányi, 1967; Aumann, 1974). The second one is looking for the mapping of influence in negotiations.

Starting with sequential modelling, Forgó et al. (2003) gives a good summary of the Harsányi model, which takes incomplete information into account.

"The Harsanyi model calls for condensing all uncertainty a game might involve in defining different types of players, each characterized by a specific information (attribute) vector whose actual occurrence is governed by chance. Chance then determines which types of players will actually play the game. Each player knows his own type but has only a subjective probability distribution about the types of the rest of the players. Harsanyi's basic assumption (usually referred to as Harsanyi's doctrine) is that there is a common prior distribution defined over all possible types of all players whose conditional probabilities (conditioned on each player's own type) coincide with the posterior subjective probabilities of the players. Expected payoffs can then be defined in terms of the common prior (or as shown by Harsanyi, equivalently in terms of the posterior probabilities) and the game with incomplete information be reduced to a game with complete information in which the Nash equilibrium will provide the same solution we would have obtained in the original game (of incomplete information) if Bayesian rationality is assumed of the players

\footnotetext{
${ }^{5}$ There are examples for both. The Nazi Germany in the 1930s or the USA in the cold war used their power for economic advantages. In the period from the 1960s to the 1980s, Japan and West Germany their economic wealth to have international power as they were forbidden to keep a strong military force.
} 
each player to maximize his own expected payoff using his subjective (posterior) probabilities about the behaviour of the rest of the players." Forgó et al. (2003, p. 255)

Myerson (1997, p. 75) demonstrated the incomplete information situation when there are no clear answer opportunities but players must figure out the possible answers from their limited knowledge. Uncertainty and the limited empirical experience on warming make the climate change problem such an incomplete information game, since there is no consensus about the optimum ways and forms of mitigation.

The Harsányi model was further developed and continued in the correlated equilibrium for two players by Aumann (1974) and for more than two players by Aumann (1987) with a bimatrix game. The correlated equilibrium is based on the normal form of a non-cooperative game. The complex version has critical point, as

"when the game is originally defined in extensive form and is given by the game tree, then going from the extensive form to the normal form entails both a large growth in size and we also lose some of the direct, intuitive meaning of a CE since the basic idea gets across through the mediation of the very complex strategies used in the normal form." (Forgó et al., 2003, p. 259)

Tree construction is a methodological instrument in simultaneous game theory to illustrate all possible alternatives that can be taken in an iteration process when players decide one by one after each other. The tree model can simultaneously represent all possible payoffs and more than two players, thus easing the decision in a repeated finite or infinite game. Trees are also useful to incorporate the uncertainty through the probability values of the individual branches of a tree. In parallel, the tree model can follow the repeated actions caused by one-by-one individual strategic choices, too, and detach the opponents' actions limited by a previous action in the iteration process. (Dixit \& Skeath, 1999, p. 45-54, 176-178)

In the correlated equilibrium model adapted by Forgó et al. (2003) from Aumann (1987), each player can make a single step in a given sequence before any other player acts in the next round. Thus, this assumption gives opportunity to draw the sequence of decision options as a tree. This results in a so called tree-correlated equilibrium model derived by Forgó et al. (2003) from the Aumann model. The Forgó-Fülöp-Prill model or treecorrelated equilibrium model (Figure 9) assumes that there is a game tree of an extensive game with perfect information and probability distributions assigned to every non-terminal node, and the probabilities are known for each player. There is a moderator in the game, and the players react blindly to the moderator's hidden proposals. The options are acceptance or rejection. Forgó et al. (2003) have two ways for the solution of the game: the Nash bargaining solution and the Kalai-Smorodinsky bargaining solution.

Figure 9 Example of a tree-correlated equilibrium model

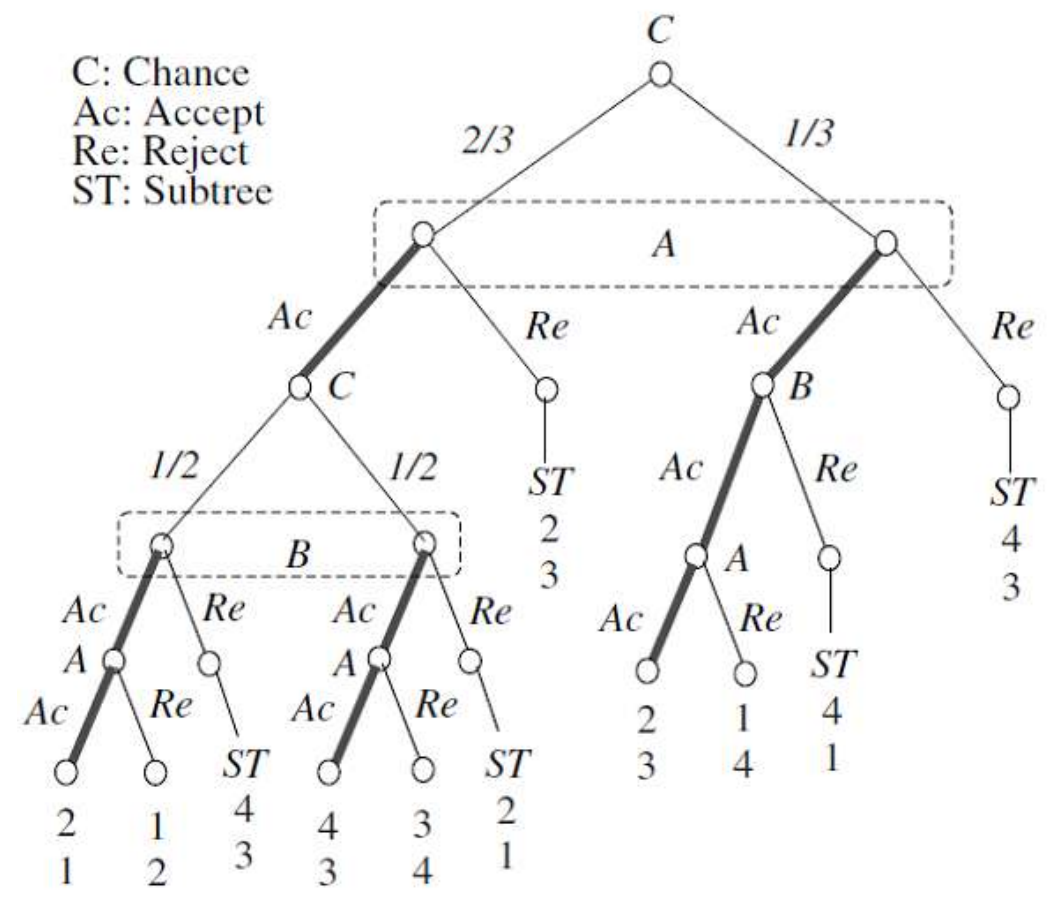

Source: Forgó et al. (2003, p. 260, Figure 3) 
Similarly to the correlated equilibrium model, Rausser and Simon (1991) can be viewed as an extension of Rubinstein (1982), who developed the multilateral bargaining model in which there is no moderator but Player 1 makes an offer, which player 2 can accept or reject. In the case of rejection, game is repeated and bargaining can go on for an infinite number of times. This model has been used by Pinto \& Harrison (2003), where the players are the seven regions/countries constituting the OECD. The countries select from policy vectors and create collations. "The policy vector consists of a specific emission cut and a specific year to attain it. The proposed coalition must be an admissible coalition as previously defined." (Pinto \& Harrison, 2003p. 921) The model was specified for carbon regulation with and without quota trade.

Table 3 TCCF model

Objective function of the model
Max $\Pi_{i, t}=\sum_{t} \frac{U_{i, t}}{\left(1+\delta_{t}\right)^{t}}$ with $U_{i, t}=L_{i, t} \log \left(\frac{C_{i, t}}{L_{i, t}}\right)$

Source: Courtois \& Tazdaït (2007, p. 303)

Influence in climate change negotiations is modelled by the Tóth-Ciscar-Courtois-Forgó stochastic model (TCCF) by Tóth et al. (2001), and used for simulation by Courtois \& Tazdaït (2007) based on RICE model. RICE is the acronym for Regional Integrated model of Climate and the Economy, developed by Nordhaus \& Yang (1996) and Nordhaus \& Boyer (1999). Incidentally, Yang (2003) made a coalition simulation based on the RICE model of climate change negotiations, and modelled the behaviour of big powers like China, USA etc. In the case of influence modelling, the methodological study of Courtois (2002) can be mentioned as an early mapping of climate change negotiations by vector and matrix analysis. ${ }^{6}$

\footnotetext{
${ }^{6}$ Courtois \& Tazdaï (2007) illustrated the climate change negotiation games with the following situation: "Each country sends a delegate to a negotiation round. Each delegate knows to which coalition his country belongs. He knows also his country's payoff in any action profile. Consider pair wise interactions. The two countries' delegates meet each other and interact. We distinguish four types of interactions. The ones leading to imitation, to persuasion, to dissuasion and to avoidance. They can be grouped into two categories. First category is the tendency for a country to follow the action of another. A country's delegate can persuade another to adopt a similar policy. He can call for another country to follow his example or dissuade another from playing
} 
The TCCF model is built on an equilibrium framework using traditional economic concepts regarding optimization and capital accumulation. It is a parameterized formulation of a problem, and allows the evaluation of countries' payoffs on the basis of key policy variables such as capital accumulation and carbon emission control rates. Players optimize their economic welfare taking into consideration the trade-off that the emission of greenhouse gases means production and damage together, both expressible in economic terms. The model has a built-in carbon-energy variable related to the energy intensity by carbon emissions. The geophysical module of the TCCF model contains three groups of equations describing the causal chain: emission - concentration global change, Courtois \& Tazdaït (2007, p. 303).

\section{Conclusions $^{7}$}

The game theory offers a broad background for the modelling and examination of stakeholders' behaviour affected by climate change challenges and damages. However, the high number of actors, variables, and the high level of uncertainty limits the opportunities of game theory modelling. Through the game theory, it is possible to illustrate the dilemmas and strategic options of a group of actors, thus making the very complex relationship of industrial activity, carbon emission, climate change, ecological and economic damages transparent for decisionmakers at the levels of economic diplomacy, public policy, or private business.

We can conclude that the carbon emission and the climate can be surveyed in the most efficient way if we consider them as a common pool resource for international relations. By this approach and the well-developed general theories and empirical experience on CPR problem, we can create adequate strategies, recommendations, conclusions for the appropriate mitigation and adaptation to global warming.

The negation games applied for climate negotiations provide opportunities to quantify and compare the varied and diversified interests, cost, damages, benefits represented by hundreds of countries and an uncountable number of businesses, households, NGOs etc. as actors. Besides, the negotiation games provide an opportunity to discover how to convince reluctant players to participate in mitigation and adaptation.

\section{Acknowledgement}

This study was funded by TAMOP-4.2.1.B-09/1/KMR-2010-0005 project of the New Szechenyi Plan of the Hungarian Government and the European Union.

\section{References}

Abreu, D., Dutta, P., and Smith, L. (1994) 'The Folk Theorem for Repeated Games: A NEU condition', Econometrica vol. 62, pp. 939-948.

Abreu, D., Pearce, D. and Stacchetti, E. (1990) 'Towards a Theory of Discounted Repeated Games with Imperfect Monitoring', Econometrica vol. 58, pp. 1041-1064.

Aumann, R.J., (1974) 'Subjectivity and correlation in randomized strategies' Journal of Mathematical Economics vol. 1, pp. 67-96.

differently. For instance, an environmentalist country can persuade others to cooperate. On the other hand, this same country can prefer to defect if confronted with a majority of countries who want to defect. Second category is the tendency for a country to adopt the opposite action from the one adopted by another. This is fight or avoidance. For example, a country who is aware of the formation of a large cooperative agreement can decide to defect although he initially wanted to cooperate. Also, a country can decide to cooperate if another defects in order to avoid irreversible damages. Finally, one can conceive of a situation in which a country fights with another and decides to adopt an action which is the opposite of the one played by his opponent."

${ }^{7}$ For useful constructive comments and suggestions, I am grateful to the anonymous reviewers; all errors remain mine. 
Aumann, R.J., (1987) 'Correlated equilibrium as an expression of Bayesian rationality' Econometrica vol. 55, pp. 1-18.

Barrett, S., (1994) 'Self-enforcing international environmental agreements' Oxford Economic Papers vol 46, pp. 878-894.

Berger, S., (2008) 'Circular cumulative causation (CCC) a la Myrdal and Kapp — political institutionalism for minimizing social costs’ Journal of Economic Issues vol. 42, pp. 357-366.

Berger, S. (Ed.), (2009) The Foundations of Non-Equilibrium Economics: The Principle of Circular and Cumulative Causation. Routledge, Oxon. NY.

Carraro, C. and Siniscalco, D., (1993) 'Strategies for the international protection of the environment' Journal of Public Economics vol. 52, pp. 309-328.

CEPS \& ZEW (2010) The Fiscal Implications of Climate Change Adaptation Final Report № ECFIN/E/2008/008

Chander, P. and Tulkens, H., (1995) 'A core-theoretical solution for the design of cooperative agreements on trans-frontier pollution’ International Tax and Public Finance vol. 2, pp. 279-294.

Ciscar, J.C. and Soria, A., (2002) 'Prospective analysis of beyond Kyoto climate policy: A sequential game framework’ Energy Policy vol. 30, pp. 1327-1335.

Coase R.H. (1960) 'The Problem of Social Cost' Journal of Law and Economics, October

Courtois, P. and Tazdaï, T. (2007) 'Games of influence in climate change negotiations: Modelling interactions Ecological Modelling no. 204 pp. 301-314

Courtois, P. (2002) 'Influence Processes in Climate Change Negotiations: Modelling the Rounds' NOTA DI LAVORO Fondazione Eni Enrico Mattei 86.2002 OCTOBER CLIM- Climate Change Modelling and Policy http://www.feem.it/web/activ/_activ.html

Dawes, R. M. (1973) 'The Commons Dilemma Game: An N-Person Mixed-Motive Game with a Dominating Strategy for Dawes, Robyn M. Defection.' ORI Research Bulletin, vol. 13, no. 2 (Sept.), 1-12.

Dawes, R. M. (1975) 'Formal Models of Dilemmas in Social Decision Making.' In Martin F. Kaplan and Steven Schwartz, eds., Human Judgment and Decision Processes: Formal and Mathematical Approaches. New York: Academic Press.

Demsetz, H. (1967) 'Toward a Theory of Properly Rights.' American Economics Review, vol. 62, no. 2 (May), 347-359.

Dixit, A. K. and Skeath, S. (1999) Games of Strategy Norton (page numbers refer to the $2^{\text {nd }}$ edition in 2004 
Forgó F., Fülöp J. and Prill, M. (2005) 'Game theoretic models for climate change negotiations' European Journal of Operational Research vol. 160, pp. 252-267

Forgó F. , Szép J. and Szidarovszky F., (1999) Introduction to the Theory of Games. Kluwer Academic Publishers, Dordrecht.

Fudenberg, D., Levine, D. and Maskin, E. (1994) 'The Folk Theorem with Imperfect Public Information' Econometrica vol. 62, pp. 997-1040.

Garnaut, R., (2008) The Garnaut Climate Change Review: Final Report. NY. Cambridge University Press, Cambridge, UK.

Gowdy, J.M. (2008) 'Behavioral economics and climate change policy' Journal of Economic Behavior \& Organization vol 66., pp. 632-644

Haass, R.N. (2008) ‘The Age of Non-Polarity’ Foreign Affairs May/June 2008

Hammitt, J. K. and Adams, J. L. (1996) 'The value of international cooperation for abating global climate change' Resource and Energy Economics vol. 18 pp. 219-241

Hardin, G (1968) 'The Tragedy of the Commons' Science vol 162 pp. 1243-8

Harsanyi, J.C., (1967) 'Games with incomplete information played by “'Bayesian” players I-III.' Management Science vol. 14, pp. 159-182, 320-334, 486-502.

Harsanyi J. C. and Selten R. (1988) A General Theory of Equilibrium Selection in Games. Cambridge, MA: The MIT Press

Hasson, R., Löfgren, Å. and Visser, M. (2010) 'Climate change in a public goods game: Investment decision in mitigation versus adaptation' Ecological Economics vol. 70 pp. 331-338

Ikenberry G.J. (2008) 'The Rise of China and the Future of the West' Foreign Affairs January/February 2008

IPCC. (Intergovernmental Panel on Climate Change), (2007a). 'Intergovernmental Panel on Climate Change' In: Solomon, Susan, Qin, Dahe, Manning, Martin, Marquis, Melinda, Averyt, Kristen, Tignor, Melinda, HenryJr Jr, Miller, Chen, Zhenlini (Eds.), Climate Change 2007-The Physical Science Basis. Contribution of Working Group I to Fourth Assessment Report. Cambridge University Press, New York.

IPCC. (Intergovernmental Panel on Climate Change), (2007b). 'Climate Change 2007- Impacts, Adaptation and Vulnerability' In: Parry, Martin, Canziani, Osvaldo, Palutikof, Jean, van der Linden, Paul, Hanson, Clair (Eds.), Contribution of Working Group II to Fourth Assessment Report. Cambridge University Press, New York.

IPCC. (Intergovernmental Panel on Climate Change, (2007c). 'Climate Change 2007 Mitigation of Climate Change' In: Metz, Bert, Bosch, Peter, Dave, Rutu, Davidson, Ogun,Mayer, Leo (Eds.), Contribution of Working Group III to Fourth Assessment Report. Cambridge University Press, NY. 
IPCC. (Intergovernmental Panel on Climate Change, (2007d.) 'Climate Change 2007' Synthesis Report. IPCC. $73 \mathrm{pp}$.

Jansen, M. and de Vries, B. (1998) 'The battle of perspectives: a multi-agent model with adaptive responses to climate change' Ecological Economics vol. 26 pp. 43-65

Kandori, M. (2006) 'Repeated Games' In: Durlauf, S. N. - Blume, L. E. (2006) The New Palgrave Dictionary of Economics Palgrave

Keohane, R. O. and Hoffmann, S. (1991) The New European community : decisionmaking and institutional change Westview Press

Keohane, R. O. (1989) International institutions and state power : essays in international relations theory Westview Press

Keohane R.O. (1984) After Hegemony. Cooperation and Discord in the World Political Economy Princeton University Press, Princeton

Keynes, J.M., (1936). The General Theory of Employment. Interest and Money. BN Publishing, London. 2008.

Keynes, J.M., (1921). A Treatise on Probability. Rough Draft Printing, New York. 2008.

Knight, F.H., (1921). Risk, Uncertainty and Profit. Cosimo Classics, New York.

Maynard Smith, J. (1982) Evolution and the Theory of Games Cambridge University Press

McKelvey, R., Miller, K.A. and Golubtsov P (2003) 'Fish-wars revisited a stochastic incomplete-information harvesting game' In: Wesseler, J., Weikard, H.P. and Weaver RD (eds) Risk and uncertainty in environmental and natural resources economics. Edward Elgar Publishing, Northampton, MA, p 93-112

Myerson, R.B. (1997) Game Theory: Analysis of Conflict Harvard University Press

Nordhaus, W. and Boyer, J.G., (1999). Warming the World: Economics Model of Climate Change. MIT press, Cambridge MA.

Nordhaus, W.D. and Yang, Z., (1996) 'RICE: A regional dynamic general equilibrium model of alternative climate change strategies.' The American Economic Review vol. 86, pp. 726-741

O'Hara P. A. (2009) 'Political economy of climate change, ecological destruction and uneven development' Ecological Economics vol. 69 pp. 223-234

Olson, M. (1965) The logic of collective action: public goods and the theory of groups Harvard University Press 
Osborne, M.J. and Rubinstein, A., (1996) A Course in Game Theory. The MIT Press, Cambridge, MA.

Ostrom, E. (1990) Governing the Commons. The Evaluation of Institutions for Collective Actions Cambridge University Press

Owen, G. (2008) Game Theory 3rd. edition, Emerald, Bingley, 1st edition in 1969, Saunders

Peck, S.C. and Tijsberg, T.J., (1999) 'CO2 concentration limits, the costs and benefits of control and the potential for international agreements' In: Carraro, C. (Ed.), International Environmental Agreements on Climate Change. Kluwer Academic Publishers, Dordrecht.

Pinto, L.M. and Harrison, G. W. (2003) 'Multilateral negotiations over climate change policy’ Journal of Policy Modeling vol. 25, pp. 911-930

Ravenhill, J., Aggrawal, V.K. and Dupont, C. (2005) Global Political Economy. Oxford University Press

Rasmusen E (1992) Games and information an introduction to game theory, reprint with corrections. Blackwell Publishers, Oxford

Rausser, G., and Simon, L. (1991). 'A noncooperative model of collective decision making: A multilateral bargaining approach’ Working Paper No. 618. Department of Agricultural and Resource Economics, University of California at Berkeley.

Rubas, D.J., Hill, H.S.J. and Mjelde, J.W. (2006) 'Economics and climate applications: exploring the frontier' Climate Research vol. 33, pp. 43-54

Rubinstein, A. (1982). Perfect equilibrium in a bargaining model. Econometrica, vol. 50, pp. 97-109.

Shackle, G.L.S., (1970) Expectation, Enterprise and Profit. Allen \& Unwin, London

Smith, R. J. (1981) 'Resolving the Tragedy of the Commons by Creating Private Property Rights in Wildlife.' CATO Journal, vol. 1, no. 2 (autumn), 439-468.

Stern, N., (2007) The Economics of Climate Change: The Stern Review. Cambridge University Press, Cambridge, UK.

Toth F., Ciscar, J.C., Courtois, P. and Forgo, F., (2001) 'Strategic for integrated assessment of dynamic carbon emission reduction policies’ EU SIADCERO Final Report ENG3-1999-00011, available at http://www.pik.de/.

UNDP. (United Nations Development Program), (2007) Human Development Report 2007/2008: Fighting Climate Change: Human Solidarity in a Divided World. Palgrave Macmillan, New York. Available on the Internet.

Ward, H. (1996) 'Game theory and the politics of global warming: the state of play and beyond' Political Studies vol. 44 p.850-871 
Weibull , J. W. (1995) Evolutionary game theory MIT Press

Yang, Z. (2003) 'Reevaluation and renegotiation of climate change coalitions-a sequential closed-loop game approach' Journal of Economic Dynamics \& Control 27 (2003) 1563 - 1594 